\title{
Testing the use of OSL from quartz grains for dating debris flows in Miyun, northeast
} Beijing, China

Zhao, Qiuyue ; Thomsen, Kristina Jørkov; Murray, Andrew; Wei, Mingjian ; Pan, Baolin ; Song, Bo ; Zhou, Rui ; Chen, Shuzhen ; Zhao, Xiaohong ; Chen, Hongyi

Published in:

Quaternary Geochronology

Link to article, DOI:

10.1016/j.quageo.2015.03.007

Publication date:

2015

Document Version

Peer reviewed version

Link back to DTU Orbit

Citation (APA):

Zhao, Q., Thomsen, K. J., Murray, A., Wei, M., Pan, B., Song, B., Zhou, R., Chen, S., Zhao, X., \& Chen, H. (2015). Testing the use of OSL from quartz grains for dating debris flows in Miyun, northeast Beijing, China. Quaternary Geochronology, 30(Part B), 320-327. https://doi.org/10.1016/j.quageo.2015.03.007

\section{General rights}

Copyright and moral rights for the publications made accessible in the public portal are retained by the authors and/or other copyright owners and it is a condition of accessing publications that users recognise and abide by the legal requirements associated with these rights.

- Users may download and print one copy of any publication from the public portal for the purpose of private study or research.

- You may not further distribute the material or use it for any profit-making activity or commercial gain

- You may freely distribute the URL identifying the publication in the public portal 


\section{Elsevier Editorial System(tm) for Quaternary Geochronology Manuscript Draft}

\section{Manuscript Number: QUAGEO-D-14-00169R1}

Title: Testing the use of OSL from quartz grains for dating debris flows in Miyun, northeast Beijing, China

Article Type: SI: LED14 Proceedings

Keywords: Debris flow deposits; Quartz; Single-grain dating; SAR

Corresponding Author: Prof. Mingjian Wei, ph.D

Corresponding Author's Institution: Capital Normal University

First Author: Qiuyue Zhao, ph.D

Order of Authors: Qiuyue Zhao, ph.D; Kristina J Thomsen; Andrew S Murray; Mingjian Wei; Baolin Pan; Bo Song; Rui Zhou; Shuzhen Chen; Xiaohong Zhao; Hongyi Chen

Abstract: Abstract : Extreme seasonal summer rain storms are common in the mountains to the north east of Beijing and these often result in mass movement of sediment slurries transported for up to a few $\mathrm{km}$. These debris flows can be deadly and are very destructive to infrastructure and agriculture. This project tests the application of luminescence dating to determining the return frequency of such extreme events. The high sediment concentration and the very short flow duration gives very little opportunity for daylight resetting during transport and only a small fraction of the total mass is likely to be reset before transport begins. Here we examine the quartz single-grain dose distribution from a recent known-age $(<25$ years) debris flow from a small $(\sim 3.9 \mathrm{~km} 2)$ catchment $\sim 140 \mathrm{~km}$ north of Beijing and compare it with those from three samples from a sedimentary sequence containing the evidence of multiple flow events. Multi-grain quartz OSL signals are dominated by the fast component and $<1 \%$ of the $150-200 \mu \mathrm{m}$ grains give a detectable test dose ( $4.5 \mathrm{~Gy}$ ) response. Single-grain beta dose recovery gave a ratio of $0.97 \pm 0.06(n=30)$ with an over-dispersion of $23 \pm 8 \%$ (CAM). Both the recent known age and the paleo-distributions are highly dispersed with over-dispersions greater than $50 \%$. The average weighted doses range between $\sim 3 \mathrm{mGy}$ and $\sim 6.5 \mathrm{~Gy}$, indicating that all deposits are no more than a few thousand years. Minimum age modelling give an age estimate for the youngest sample consistent with the known age, and minimum ages for the older fossil deposits suggest that there have been at least 3 major debris flows in this small catchment in the last 1000 years. 


\section{Testing the use of OSL from quartz grains for dating debris flows in Miyun, northeast Beijing, China}

Qiuyue Zhao ${ }^{1}$, Kristina Jørkov Thomsen ${ }^{2}$, Andrew Sean Murray ${ }^{3}$, Mingjian Wei $^{1 *}$, Baolin Pan ${ }^{1}$, Bo Song ${ }^{1}$, Rui Zhou ${ }^{4}$, Shuzhen Chen ${ }^{1}$, Xiaohong Zhao ${ }^{1}$,Hongyi Chen ${ }^{1}$ ${ }^{1}$ College of Resource Environment and Tourism-Capital Normal University, 100048 Beijing, China

${ }^{2}$ Center for Nuclear Technologies, Technical University of Denmark, DTU Ris $\phi$ Campus, Frederiksborgvej 399, 4000 Roskilde, Denmark

${ }^{3}$ Nordic Laboratory for Luminescence Dating, Department of Geoscience, University of Aarhus, Risø Campus, Frederiksborgvej 399, 4000 Roskilde, Denmark

${ }^{4}$ Institute of Earthquake Science, CEA, 100036 Beijing, China

* Corresponding author.Tel:+86 1068907004

E-mail address:weimj@cnu.edu.cn

Abstract

Extreme seasonal summer rain storms are common in the mountains to the north east of Beijing and these often result in mass movement of sediment slurries transported for up to a few $\mathrm{km}$. These debris flows can be deadly and are very destructive to infrastructure and agriculture. This project tests the application of luminescence dating to determining the return frequency of such extreme events. The high sediment concentration and the very short flow duration gives very little opportunity for daylight resetting during transport and only a small fraction of the total mass is likely to be reset before transport begins. Here we examine the quartz single-grain dose distribution from a recent known-age $(<25$ years $)$ debris flow from a small $\left(\sim 3.9 \mathrm{~km}^{2}\right)$ catchment $\sim 140 \mathrm{~km}$ north of Beijing and compare it with those from three samples from a sedimentary sequence containing the evidence of multiple flow events.

Multi-grain quartz OSL signals are dominated by the fast component and $<1 \%$ of the 150-200 $\mu \mathrm{m}$ grains give a detectable test dose (4.5 Gy) response. Single-grain beta dose recovery gave a ratio of $0.97 \pm 0.06(n=30)$ with an over-dispersion of $23 \pm 8 \%$ (CAM). Both the recent known age and the palaeo-distributions are highly dispersed with over-dispersions greater than $50 \%$. The average weighted doses range between $\sim 3 \mathrm{mGy}$ and $\sim 6.5 \mathrm{~Gy}$, indicating that all deposits are no more than a few thousand years. Minimum age modelling give an age estimate for the youngest sample consistent with the known age, and minimum ages for the older palaeo-deposits 
suggest that there have been at least 3 major debris flows in this small catchment in the last 1000 years.

Keywords: Debris flow deposits; Quartz; Single-grain dating; SAR

\section{INTRODUCTION}

Debris flows are a common mass-movement process which have repeatedly led to mortality and important economic loss in high relief areas of the world, especially in China with its historically high population density (Fiorillo and Wilson, 2004; Yang et al., 2011; Tang et al., 2012). The Xiao Xi Tian catchment (Fig. 1) is typical of small catchments to the north of Beijing, and lies upstream of the Miyun reservoir (the largest water supply storage for Beijing). Floods and resulting debris flows in such catchments have important implications for water quality and storage capacity (Xie et al., 2001; Qin et al., 2001); they also have a direct impact on infrastructure and the lives of local people. Even in China, where documentary records have a long history, such events are not well documented. In order to estimate accurately the hazard of debris flow events, we need tools for dating the sediments deposited by these events, so that we can relate these to climate variations, and so estimate the return frequency.

Optically Stimulated Luminescence (OSL) is one such potential tool. Unfortunately, debris flows result in poor sorting, rapid sedimentation and very little opportunity for light exposure. This inevitably results in extremely heterogeneous resetting of the OSL signal. The relationship between bleaching and mineral type was considered by Godfrey-Smith et al. (1988), Fuchs et al. (2005) and Murray et al. (2012) and Olley et al. (1998) and Fuchs et al. (2005) examined the dependence of bleaching on grain size. It is now well known that quartz OSL signals bleach more easily than those from feldspar, and in many cases it appears that coarser (sand-sized) grains are easier to bleach than fine (silt-sized) grains. Because of averaging, multi-grain aliquots will tend to systematically overestimate the dose absorbed by well-bleached grains (e.g. Olley et al., 1998). Ultimately dose measurements on individual grains are required if the well-bleached fraction is to be identified and quantified. Wu et al. (2010) have found that using the lowest 5\% of the apparent 
single-grain doses (Murray et al., 1995) helped to distinguish the best bleached grains from the incompletely bleaching grains, indicating the potential for applying single grain luminescence dating to debris flow deposits in a mountainous regime from western Taiwan but there has been little or no testing of this approach on palaeo-debris flows. There are also more sophisticated statistical tools available for identifying the well-bleached part of a dose distribution (e.g. the minimum age model, MAM, Galbraith et al., 1999, the internal/external consistency criterion, IEU, Thomsen et al., 2007), but these have not been applied before to palaeo-debris flows.

The aim of this study is to derive quartz OSL burial ages for four samples collected from the Xiao Xi Tian catchment: one documented recent $(<25$ a) deposit and three unknown age palaeo-debris flows. Multi-grain aliquot ( 200 grains each) measurements are used to establish the suitability of these samples for OSL dating. As these samples are likely to suffer from significant incomplete bleaching the main emphasis is placed on single-grain OSL measurements. Single-grain thermal transfer and dose recovery experiments are undertaken and the burial doses evaluated by applying various minimum age models to the measured dose distributions. Finally these ages are discussed in terms of return frequency.

\section{REGIONAL SETTING}

The study site (Fig. 1) is situated in the Xiao Xi Tian gully (between $40^{\circ} 43^{\prime} 21.38^{\prime \prime}$ and $40^{\circ} 43^{\prime} 23.54^{\prime \prime} \mathrm{N} ; 116^{\circ} 51^{\prime} 00.72^{\prime \prime}$ and $\left.116^{\circ} 51^{\prime} 1.31^{\prime \prime} \mathrm{E}\right)$ a tributary of the seasonal Fanzipai west gully, which ultimately flows into the Bai River and the Miyun reservoir. The catchment area upstream of the sampling site is $\sim 3.9 \mathrm{~km}^{2}$ and the upstream length of the main channel is $\sim 4 \mathrm{~km}$. The local geology is dominated by granite and gneiss, and the catchment lies in the warm temperate sub-humid monsoon climate zone, with frequent rain storms between June and August; this period includes $\sim 73 \%$ of the annual $660 \mathrm{~mm}$ precipitation (Tu, 1994). Over the Miyun district as a whole, the mapped area of debris flows is about $28 \%$ of the total catchment area; this 
represents a clear and ongoing threat to infrastructure and human life. The only documented debris-flow in the catchment was in 1989 (Tu, 1994).

\section{SAMPLE AND MEASUREMENT DETAILS}

\subsection{SAMPLING}

Four samples were collected from the Xiao Xi Tian (XXT) gully. A recent debris flow sample (XXT-1) was taken from the bed of the river channel and three palaeo-debris flow samples were collected from two incised debris flow terraces (Fig. 1). Sample XXT-2 was taken from the lower terrace. Samples XXT-3 and XXT-4 were taken from the higher terrace. The exposed section was cut vertically and cleaned to expose the mainly cobble/gravel deposits. Samples were taken by driving $10 \mathrm{~cm}$ diameter $25 \mathrm{~cm}$ long steel tubes into the section. Both ends of the tube were packed with aluminium foil and wrapped to prevent sample mixing during transport. Samples were opened under subdued red light and $3 \mathrm{~cm}$ from each end of the tubes were removed for dose rate analysis and water content measurement; the remainder was prepared for OSL measurement (see below).

Sample XXT-1 (Fig. 1) was taken from the recent ( $<25$ year old) debris flow sample. The other three samples are of unknown age, but stratigraphically older. We expect sample XXT-3 to be the oldest deposit, overlain by the younger sample XXT-4. The river then incised and later deposited the younger debris flow deposit (XXT-2) some time before XXT-1.

\subsection{SAMPLE REPARATION}

The material taken for OSL measurements was firstly wet sieved to recover grain sizes between 150 and $200 \mu \mathrm{m}$. This fraction was then treated with $10 \% \mathrm{HCl}$ to remove carbonates, and $10 \% \mathrm{H}_{2} \mathrm{O}_{2}$ to remove organic matter. Density separation used aqueous solutions of density 2.58 and $2.7 \mathrm{~g} \mathrm{~cm}^{-3}$ to separate quartz grains, which were 
then etched in $40 \% \mathrm{HF}$ for $1 \mathrm{~h}$, and washed in $10 \% \mathrm{HCl}$ to remove any fluoride precipitates. The purity of quartz was checked by infrared stimulation. Some of the samples showed a significant IRSL signal, and these were treated again with $40 \% \mathrm{HF}$ for 40 minutes. After this double treatment, no sample gave a significant IR signal (compared to blue OSL). All samples were re-sieved after chemical treatment to give grains in the range of $125-180 \mu \mathrm{m}$.

\subsection{INSTRUMENTATION AND ANALYSIS}

Quartz OSL measurements were made using Ris $\varnothing$ TL/OSL-DA-20 readers (Bøtter-Jensen et al., 2010) fitted with single-grain laser attachments (Bøtter-Jensen et al., 2003). Luminescence was detected by a bialkali EMI 9235QB photomultiplier tube through a $7.5 \mathrm{~mm}$ Hoya U-340 filter. Optical stimulation used either an array of blue LEDs (multi-grain measurements) providing a power density of $\sim 40 \mathrm{~mW} \mathrm{~cm}^{-2}$ at the sample position or a $10 \mathrm{~mW}$ green $\mathrm{Nd}: \mathrm{YVO}_{4}$ solid diode-pumped laser emitting at $532 \mathrm{~nm}$ (single-grain measurements) providing a power density of $\sim 50 \mathrm{~W} \mathrm{~cm}^{-2}$ at the stimulation position (Duller et al., 1999). Blue LED stimulation was for $40 \mathrm{~s}$ at $125^{\circ} \mathrm{C}$ whereas green laser stimulation was for $0.9 \mathrm{~s}$ at $125^{\circ} \mathrm{C}$. For multi-grain measurements quartz grains were mounted as a monolayer on $9.7 \mathrm{~mm}$ stainless steel discs using silicon oil. Each multi-grain aliquot contained $\sim 200$ grains. For single-grain measurements individual grains were loaded into aluminium discs containing 100 grain holes, each with a diameter and depth of $200 \mu \mathrm{m}$, set out on a square grid with $600 \mu \mathrm{m}$ hole spacing. Laboratory irradiations employed ${ }^{90} \mathrm{Sr} /{ }^{90} \mathrm{Y}$ beta source fitted on the readers with a dose rate of $\sim 0.10 \mathrm{~Gy} / \mathrm{s}$ to quartz grains in single-grain aluminium discs. These sources all had good spatial uniformity ( $<5 \%$ standard deviation across the sample area) and using the approach developed by Lapp et al. (2012) to correct for spatially non-uniformity did not result in significant changes to dose or scatter.

All OSL measurements were performed using a SAR protocol (Murray and Wintle, 2000; Wintle and Murray, 2006). For single-grain measurements a minimum of two regeneration doses ( 2 and $10 \mathrm{~Gy}$ ) was measured in increasing order. In some 
cases an additional regeneration dose of $80 \mathrm{~Gy}$ was added to ensure that larger doses were measured accurately. A zero Gy (recuperation) dose and a recycling dose equal to the second regeneration dose $(10 \mathrm{~Gy})$ were used to test the reliability of the dose response curve. A preheat of $200{ }^{\circ} \mathrm{C}$ for $10 \mathrm{~s}$, a cut heat of $180^{\circ} \mathrm{C}$, heating rate of $5^{\circ} \mathrm{C}$ $\mathrm{s}^{-1}$, and 4.5 Gy test dose were used in all measurements unless otherwise specified.

Multi-grain signals were derived from the summation of the initial $0.64 \mathrm{~s}$ of stimulation, less a background of the following $0.64 \mathrm{~s}$ of stimulation. Single-grain signals were derived from the summation of the first $0.06 \mathrm{~s}$ of the stimulation curves, less a background of the final $0.16 \mathrm{~s}$ of stimulation. Sensitivity corrected dose-response curves were fitted using a single saturation exponential function, passing through the origin. The uncertainties on individual dose $\left(D_{e}\right)$ estimates are assigned using “Analyst 4.00” (Duller, 2007) and are derived by error propagation from counting statistics and curve fitting.

Multi-grain and single-grain dose estimates were only accepted for later analysis if they satisfied four criteria : (1) the relative uncertainty of the natural test dose signal $\sigma_{\mathrm{Tn}}$ was $<30 \%$; (2) the recycling ratio was consistent with unity at $2 \sigma$; (3) the OSL IR depletion ratio (Duller, 2003) was consistent with unity at $2 \sigma$; (4) the sensitivity corrected recuperation signal (i.e. the OSL signal in response to a zero Gy regenerative dose) was consistent with zero at $2 \sigma$. These criteria rejected $>99 \%$ of the measured single grains and $\sim 5 \%$ of the multi-grain aliquots.

\section{DOSE RATES}

Environmental dose rates were measured using $>70 \mathrm{~g}$ of homogenized material derived from the sampling tubes. The ground sediment was cast in wax in a defined counting geometry and stored for $>21$ days to ensure equilibrium between ${ }^{226} \mathrm{Ra}$ and ${ }^{222} \mathrm{Rn}$. The samples were then counted using calibrated high resolution gamma spectrometers (Murray et al., 1987). The resulting radionuclide concentrations of ${ }^{238} \mathrm{U}$, ${ }^{232} \mathrm{Th}$ and ${ }^{40} \mathrm{~K}$ were converted to specific dose rate values (Table 1) using the conversion factors of Guérin et al. (2011), and the cosmic ray contribution assessed 
according to Prescott and Hutton (1994). The water content is taken as midway between observed and saturated water content, because the observed value is measured on a well-drained naturally-cut exposed section. We consider it very likely that at the time of sampling the section was dryer than it had ever been during burial. Had we instead used the observed field water content in the dosimetric calculations the ages would have decreased by $19 \%$ on average.

\section{MULTI-GRAIN ALIQUOT MEASUREMENTS}

Multi-grain aliquots (containing 200 grains each ) were initially measured to assess the suitability of these samples. Fig.2a (inset) presents representative OSL stimulation curves from sample XXT-2. Also shown is the OSL signal obtained from calibration quartz, which is known to be fast component dominated (Jain et al., 2003) implying that the initial OSL signals from these samples are fast component dominated. The dose response curve (see Fig. 2a) is well represented by a single saturating exponential function.

Thermal transfer as a function of preheat temperature was measured by bleaching unheated aliquots twice with blue light for $100 \mathrm{~s}$ at room temperature with an intervening pause of $10 \mathrm{ks}$ to allow charge optically transferred into the $110{ }^{\circ} \mathrm{C} \mathrm{TL}$ peak to decay. The preheat temperature varied between 180 and $280{ }^{\circ} \mathrm{C}$ (in increments of $20{ }^{\circ} \mathrm{C}$ ). For sample XXT-1 eight aliquots were measured at each preheat temperature, and the average doses are shown in Fig. 2b. Thermal transfer is the process of de-trapping charge from non-light-sensitive but thermally shallow traps and re-trapping in deeper light-sensitive OSL traps during preheat; this can result in the overestimation of ages if OSL from the transferred charge is sufficiently large compared to the natural OSL. It is thus especially important to quantify thermal transfer when dating young sediments. In our case all average dose estimates for the different preheat temperatures are consistent with the average $0.13 \pm 0.03$ Gy $(n=48)$. Based on these results a preheat temperature of $200^{\circ} \mathrm{C}$ was chosen. Finally, we undertook a dose recovery experiment using multi-grain aliquots ( 200 grains each; 
given dose $4.5 \mathrm{~Gy})$ using a preheat temperature of $200^{\circ} \mathrm{C}(10 \mathrm{~s})$, and obtained an average dose recovery ratio of $0.94 \pm 0.04(n=6)$ for sample XXT-3. This demonstrates that our protocol is able to measure accurately a dose given in the laboratory prior to any thermal treatment.

Multi-grain equivalent doses were measured for each of the four samples. Weighted mean dose for each sample (see Table 2) is calculated using the unlogged Central Age Model (CAM UL, Arnold et al., 2009; Medialdea et al.,2014). However, all dose distributions appear positively skewed which may indicate the presence of incomplete bleaching. In that case the $\mathrm{CAM}_{\mathrm{UL}}$ ages will overestimate the true burial ages even if thermal transfer is taken into consideration.

\section{SINGLE-GRAIN MEASUREMENTS}

It is well-known that the brightness of the OSL signals generally vary significantly from one grain to another and that it is common to observe grains whose OSL sensitivity varies by several orders of magnitude (e.g. Duller, 2008 and references therein). For these samples the sensitivity of accepted individual grains only vary by $\sim 1$ order of magnitude and the majority of these grains emit weak OSL signals; the median natural OSL test dose response per grain is $12 \pm 2 \mathrm{~Gy}^{-1}$ (summed over the initial $60 \mathrm{~ms}$ of stimulation, $\mathrm{n}=156)$.

\subsection{EFFECT OF REJECTION CRITERIA}

In the OSL literature it is common practice to apply a standard set of rejection criteria (see section 3.3) to reject individual aliquots with aberrant OSL characteristics in an attempt to improve the precision and accuracy of OSL ages (e.g. Jacobs et al., 2006; Arnold and Roberts, 2011; Jacobs et al., 2012). However, for these samples (three natural and two dose recovery dose distributions) the application of these rejection criteria have no significant impact on either the central dose $\left(\mathrm{CAM}_{\mathrm{UL}}\right)$ or the relative over-dispersion $\left(\mathrm{OD}_{\mathrm{UL}}\right.$; Arnold et al., 2009). The average ratio of $\mathrm{CAM}_{\mathrm{UL}}$ 
doses for the dose distributions when all rejection criteria have been used to those when all detectable grains are included (i.e. $\left.\mathrm{s}_{\mathrm{TN}}<30 \%\right)$ is $0.98 \pm 0.03(\mathrm{n}=5$ samples). The corresponding ratio for the $\mathrm{OD}_{\mathrm{UL}}$ is $1.03 \pm 0.07$ ( $\mathrm{n}=5$ samples). On average the application of all the rejection criteria leads to the rejection of $14 \pm 5 \%$ of the detectable grain population. Thus, for these samples at least, there seems to be no justification for applying these standard rejection criteria. A similar conclusion has also been reached by Thomsen et al. (2012). Despite this we have chosen to apply these standard rejection criteria for consistency with earlier published work.

\subsection{THERMAL TRANSFER AND DOSE RECOVERY}

Single-grain thermal transfer ( 0 Gy dose recovery) was measured for sample XXT-4 using a preheat of $200{ }^{\circ} \mathrm{C}$ for $10 \mathrm{~s}$ and a cutheat of $180{ }^{\circ} \mathrm{C}$. The resulting dose distribution (shown in Fig. 3a) appears to be symmetric and has an arithmetic average dose of $200 \pm 90 \mathrm{mGy}(\mathrm{n}=30)$. The corresponding $\mathrm{CAM}_{\mathrm{UL}}$ dose is $50 \pm 30 \mathrm{mGy}$. We then performed two additional dose recovery experiments using sample XXT-4. The grains were loaded into the single-grain discs and bleached as before prior to being given beta doses of 1 Gy ( $\mathrm{N}=3400$, Fig. 3b) and 4.5 Gy ( $=3600$, Fig. 3c), respectively. Dose recovery ratios calculated using $\mathrm{CAM}_{\mathrm{UL}}$ are $0.95 \pm 0.10, \mathrm{n}=28$ $(\mathrm{OD}=28 \pm 15 \%)$ and $0.97 \pm 0.06, \mathrm{n}=30(\mathrm{OD}=23 \pm 8 \%)$, respectively. In Fig. 3d we show the relationship between absolute standard deviation and absolute over-dispersion with measured dose for these three experiments.

\section{$6.3 \mathrm{D}_{\mathrm{E}}$ DISTRIBUTIONS AND ANALYSIS}

The four natural single-grain dose distributions were then measured and are shown as scatter plots in Fig. 4. Between 0.6 and $1.0 \%$ of the measured grains were accepted into the dose distribution and the majority of these grains are only weakly luminescent (see above). The dose distribution for the known-age sample (XXT-1, Fig. 4a) appears to be approximately symmetrical, whereas the dose distributions for 
the three palaeo-debris samples (Fig. 4b, 4c and 4d) appear slightly positively skewed and show a 'leading edge' at low $\mathrm{D}_{\mathrm{e}}$ values. Thus, this may indicate some degree of incomplete bleaching.

The weighted average doses calculated using the $\mathrm{CAM}_{\mathrm{UL}}$ are summarized in Table 2 and these are converted to ages in Table 3. These ages are in stratigraphic order, but it is reasonable to assume that the ages for three palaeo-debris flow samples are overestimated due to the likely presence of incomplete bleaching.

\subsubsection{IEU MINIMUM AGE MODELING}

We then applied the Internal/External Consistency Criterion (IEU, Thomsen et al., 2007) to identify the grains most likely to have been well-bleached at deposition. The IEU approach assumes the distribution of well-bleached grains is normal, and that this portion of the total distribution can be identified using the assigned uncertainties. The uncertainty on an individual dose estimate is given by Thomsen et al. (2007) as follows:

$$
\sigma_{t o t}=\sqrt{\sigma_{c}^{2}+\left(a \cdot D_{b}+b\right)^{2}}
$$

Where $\sigma_{\text {tot }}$ is the total uncertainty calculated for each individual estimated dose; $\sigma_{c}$ is the uncertainty assigned based on counting statistics and curve fitting errors; $D_{b}$ is the burial dose, and $a$ and $b$ are the slope and intercept of the linear fit to the OD data shown in Fig. 3d; this describes the variation in OD with dose in a well-bleached distribution using the beta dose recovery data of Fig. 3a,b,c. The values of $a$ and $b$ are found to be $0.23 \pm 0.08$ and $0.04 \pm 0.02 \mathrm{~Gy}$, respectively. Those grains identified as well-bleached using the values of $a$ and $b$ given above are indicated in Fig. 4 by filled symbols. The average weighted doses derived from these apparently well-bleached grains are also summarized in Table 2 and these doses are converted to ages in Table 3. The IEU identifies all the deposits as consistent with modern although the uncertainty on the oldest sample (XXT-3) is \pm 200 years. 
Table 2 also summarises the fraction of grains identified as well-bleached in the total grain population (i.e. $\mathrm{n}_{\text {w.b. }} / \mathrm{n}$ ). For the two youngest samples 80 and $58 \%$ of the grains are well-bleached, but for the stratigraphically older samples the corresponding values are only 12 and $29 \%$. While on the one hand this could arise because the older deposits are less well-bleached, we also note that the IEU result for the older two samples are both critically dependent on a single dose estimate in each distribution, i.e. $0.27 \pm 0.34$ Gy in XXT-3 and 0.05 \pm 0.02 Gy in XXT-4. Both these doses are the lowest measured for these samples and both have absolute uncertainties significantly smaller than the other grains identified as being well-bleached. As the IEU uses individual uncertainties to determine which grains are well-bleached, there is a risk that single precisely known outliers can bias the result to low doses.

If we for the moment ignore the individual uncertainties and simply calculate an arithmetic mean of the grain population identified as well-bleached, then for sample XXT-4 we obtain a dose of $0.41 \pm 0.09(n=8)$ with an absolute standard deviation of 0.25 Gy (see column $s_{w . b .}$ in Table 2). However, the beta dose recovery data suggests that the minimum possible standard deviation (for a dose of $0.4 \mathrm{~Gy}$ ) is $\sim 0.57 \mathrm{~Gy}$ (see linear relationship given in Fig. 3d). Thus, the grains identified as well-bleached form a dose distribution which has significantly less variability than that observed in the beta dose recovery experiments, suggesting that the IEU hasn't included the entire population of presumed well-bleached grains in the burial dose estimation.

If we arbitrarily ignore the apparently very low dose but well-known grain from each of the two oldest deposits and apply the IEU then the standard deviations of the accepted results become more similar to those expected from the beta dose recovery (see Table 2 and Fig. 3d). Not surprisingly, the ages of the older two samples become much greater and the oldest deposit is now $1120 \pm 140$ years old rather than $180 \pm 200$ years (if the low dose point is retained). The fraction of grains identified as well-bleached increases to 70 and $64 \%$, respectively, similar to the fractions identified for the younger samples. 


\subsubsection{UNWEIGHTED IEU}

However, we must accept that the rejection of these two very young grains is arbitrary. We are only forced into this position because they are well-known absolutely and bias any minimum age model that depends on the uncertainties on individual grains. Fuchs and Lang (2001) ignored the uncertainties associated with individual aliquots in their minimum age model applied to multi-grain aliquots. They first calculated a minimum relative standard deviation based on their beta dose recovery experiment and showed that this was independent of dose in the range of interest. They then ordered their natural doses in increasing values and compared the running relative standard deviation in their data starting with the lowest $D_{e}$ estimates with that predicted from their beta dose recovery experiment. When these two values were equal they adopted the relevant running mean as their best estimate of dose. However, in contrast to their data our beta dose recovery experiments predict that the minimum standard deviation is dose dependent, i.e. the relative standard deviations of the distributions from the two dose recovery experiments are 68 and 33\%, respectively (see Fig. 3d) and so we cannot use a fixed predicted standard deviation. Instead, we use the equation given in Fig. $3 \mathrm{~d}$ (standard deviation $=0.23 \times \mathrm{D}+0.48$ ) to predict the expected standard deviation but otherwise process the data in the same manner as Fuchs and Lang (2001). Using this approach, called the unweighted IEU (Unw.IEU), the observed standard deviations from the two older samples match the predicted standard deviations at running doses of $1.31 \pm 0.16$ Gy $(n=26$; sample XXT-4) and 2.13 \pm 0.32 Gy ( $\mathrm{n}=8$; sample XXT-3). The observed standard deviations in the two young samples never decrease to match the predicted values (i.e. the variability is always larger than that predicted from the beta dose recovery experiments), so we choose the minimum, at which the observed standard deviation is approximately $25 \%$ larger than the predicted. At this point the doses for the two younger samples are $-0.24 \pm 0.14$ Gy $(n=15$; sample XXT-1) and $0.3 \pm 0.2$ Gy $(n=17$; sample XXT-2). Both of these results are consistent with modern deposition (see Table 2) 


\subsubsection{IEU AGES WITH VARYING ODs}

In the above (weighted) IEU calculations we have assumed that the variability observed in beta dose recovery experiments mirrors the dose variability of the well-bleached grains. However, it is likely that this assumption leads to underestimation of the burial doses, because it has been shown that the variability in gamma dose recovery experiments are larger than in beta dose recovery experiments (e.g. Thomsen et al., 2005; 2012) and because environmental beta dose heterogeneity has not been taken into account (e.g. Guérin et al., 2014). To test the importance of the adopted OD (value of $a$ in equation 1), we have calculated the IEU doses (without rejecting the two low dose outliers) for ODs ranging from 23 to $50 \%$. The equivalent doses of the two younger samples do not change significantly over this range, but the equivalent doses of the two older samples increase markedly for ODs above 30\%; for an OD of $40 \%$ the equivalent doses without rejection of outliers match the equivalent doses obtained if the two outliers are rejected, i.e. ages of $360 \pm 60$ and $1070 \pm 150$ years are obtained for samples XXT-4 and XXT-3, respectively.

\section{AGES AND DISCUSSION}

The $\mathrm{CAM}_{\mathrm{UL}}$ weighted age of the youngest sample (known age $<25$ years) is $1 \pm 18$ years and the corresponding IEU age is $-9 \pm 20$ years. We conclude that the minimum age model used here (IEU) has successfully identified the majority of grains (80\%) in this distribution as well-bleached. In contrast, only $12 \%$ to $29 \%$ of grains in the two older deposits are identified as well bleached.

If we accept the uncertainties associated with individual grains and apply the IEU then all the deposits are consistent with recent deposition although the oldest has an uncertainty of \pm 200 years (Table 3 ). However, as discussed above, these results are critically dependent on the presence of an individual, low dose precisely known $D_{e}$ in each of the two older distributions. These can of course be arbitrarily rejected but we 
have no internal justification for such a course. If instead we assume that predicted statistical uncertainties on individual doses are all small compared to unidentified sources of dispersion and so discard the uncertainties on individual grain analysis, the youngest two samples remain consistent with modern deposition but the older two become $\sim 600$ and 700 years old. It is important to realise that based on internal evidence we cannot choose between these two scenarios; in theory larger data sets might help to resolve this issue but the luminescence characteristics of this material make that impractical. Until we understand the origins of these infrequent grains recording very small doses, this ambiguity cannot be resolved. Nevertheless, in our view, it is likely that the the two outlier grains (see Fig. 4c and 4d) are anomalous and that the older ages resulting from the unweighted IEU or the weighted IEU with the two outliers discarded are more likely to reflect the true ages. If that is the case, we deduce that this debris flow record starts with the XXT-3 deposit either about $~ 1100$ years ago $\left(\mathrm{IEU}_{\mathrm{rej}}\right.$ ) or $\sim 700$ years ago (unw. IEU), and this deposit was over-topped by a subsequent major event (XXT-4) 400 years ago (IEU rej $_{\text {) }}$ or $\sim 600$ years ago (unw. IEU). The river then incised at some time, and this was followed by two recent debris flows, one within the last 100 years (XXT-2), and finally the documented event $\sim 25$ years ago. The oldest two events are separated by at least one hundred years, and the most recent two events occurred within decades of each other, but there was probably a significant time gap of 300 to 500 years during which the downcutting occurred. This may reflect catchment changes (e.g. in land use), but it must also be recognised that the material sampled in the older events was all from relict deposits-they were preserved in the sedimentary sequence. In contrast, the most recent material was sampled in the channel bed, and so its preservation potential is unknown. This channel deposit may also be better bleached than the older units. In other words, such relatively well-bleached events may have occurred before and been eroded away by subsequent flows without being preserved in the stratigraphic record.

\section{CONCLUSIONS}


In conclusion, the quartz extracted from these debris flows is suitable for luminescence dating, although very few grains $(<1 \%)$ give detectable signals and most are very weak. The IEU minimum age model can successfully identify the well-bleached grains in a recent known-age deposit. Unfortunately, interpretation of the two older units is compromised by the presence of what may be one very young outlying grain in each of the two deposits. It appears that there have been major debris-flow events in this catchment every few hundred years; this return period may have decreased significantly in the last century, but this latter interpretation is compromised by differences in stratigraphic position.

\section{ACKNOWLEDGEMENTS}

This research was funded by the National Natural Science Foundation of China (NSFC, Grant No. 41471007, and partially by Grant No. 41301006, 40871017), and Beijing Municipal Natural Science Foundation Key Programme of Class B:KZ201210028034 .

\section{REFERENCES}

Arnold, L.J., Roberts, R.G., 2011. Paper I - Optically stimulated luminescence (OSL) dating of peremmially frozen deposits in north-central Siberia: OSL characteristics of quartz grains and methodological considerations regarding their suitability for dating. Boreas 40, 389-416.

Arnold, L.J., Roberts, R.G., Galbraith, R.F., DeLong, S.B., 2009. A revised burial dose estimation procedure for optical dating of young and modern-age sediments. Quat. Geochronol. 4, 306-325.

Bøtter-Jensen, L., Thomsen, K.J., Jain, M., 2010. Review of optically stimulated luminescence (OSL) instrumental developments for retrospective dosimetry. Radiat. Meas. 45, 253-257.

Bøtter-Jensen, L., Andersen, C.E., Duller, G.A.T., Murray, A.S., 2003. Developments in radiation, stimulation and observation facilities in luminescence measurements. Radiat. Meas. 37, 535-541.

Duller, G.A.T., 2008. Single-grain optical dating of Quaternary sediments: why aliquot size matters in luminescence dating. Boreas 37, 589-612. 10.1111/j.1502-3885.2008.00051.x. 
Duller G.A.T., 2007. Assessing the error on equivalent dose estimates derived from single aliquot regenerative dose measurements. Ancient TL 25, 15-24.

Duller, G.A.T., 2003. Distinguishing quartz and feldspar in single grain luminescence measurements. Radiat. Meas. 37, 161-165.

Duller, G. A. T., Bøtter-Jensen, L., Murray, A. S., Truscott, A. J., 1999. Single grain laser luminescence (SGLL) measurement using a novel automated reader. Nucl. Instrum. Methods Phys. Res. B: Beam Interact. Mater. Atoms 155 (4), 506-514.

Fiorillo, F., Wilson, R.C., 2004. Rainfall induced debris flows in pyroclastic deposits, Campania (southern Italy). Eng. Geol. 75, 263-289.

Fuchs, M., Lang, A., 2001. OSL dating of coarse-grain fluvial quartz using single-aliquot protocols on sediments from NE Peloponnese, Greece. Quat. Sci. Rev. 20, 783-787.

Fuchs, M., Straub, J., Zöller, L., 2005. Residual luminescence signals of recent river flood sediments: a comparison between quartz and feldspar of fine-and coarse-grain sediments. Ancient TL. 23(1), 25 30.

Galbraith, R.F., Roberts, R.G., Laslett, G.M., Yoshida, H., Olley, J.M., 1999. Optical dating of single and multiple grains of quartz from Jinmium rock shelter, Northern Australia: part 1, experimental design and statistical models. Archaeometry 41, 339-364.

Guérin, G., Jain, M., Thomsen, K., Murray, A., Mercier, N., Modelling dose rate to single grains of quartz in well-sorted sand samples: the dispersion arising from the presence of potassium feldspars and implications for single grain OSL dating, Quaternary Geochronology (2015), doi: 10.1016/j.quageo.2014.12.006.

Godfrey-Smith, D.I., Huntley, D.J., Chen, W.H., 1988. Optical dating studies of quartz and feldspar sediment extracts. Quat. Sci. Rev. 7(3 4), 373 380.

Jain, M., Murray, A.S., Bøtter-Jensen, L., 2003. Characterisation of blue-light stimulated luminescence components in different quartz samples: implications for dose measurement. Radiat. Meas. 37(4-5), 441-449.

Jacobs, Z., Duller, G.A.T., Wintle, A.G., 2006. Interpretation of single grain De distributions and calculation of De. Radiat. Meas. 41, 264-277.

Jacobs, Z., Roberts, R.G., Nespoulet, R., Hajraoui, M.A.E., Debénath, A., 2012. Single-grain OSL chronologies for Middle Palaeolithic deposits at El Mnasra and El Harhoura 2, Morocco: Implications for Late Pleistocene human-environment interactions along the Atlantic coast of northwest Africa. Journal of Human Evolution. 62, 377-394.

Lapp, T., Jain, M., Thomsen, K.J., Murray, A.S., Buylaert, J.P., 2012. New luminescence measurement facilities in retrospective dosimetry. Radiat. Meas.47, 803-808

Medialdea, A., Thomsen, K.J., Murray, A.S., Benito, G., 2014. Reliability of equivalent-dose determination and age-models in the OSL dating of historical and modern palaeoflood sediments. Quat. Geochronol. 22, 11-24.

Mejdahl, V., 1987. Internal radioactivity in quartz and feldspar grains. Ancient TL 5, $10-17$. 
Murray, A.S., Marten, R., Johnston, A., Martin, P., 1987. Analysis for naturally occurring radionuclides at environmental concentrations by gamma spectrometry. J. Radioanal. Nucl. Chem. 115(2), 263-288.

Murray, A.S., Olley, J.M., Caitcheon, G.G., 1995. Measurement of equivalent doses in quartz from contemporary water-lain sediments using optically stimulated luminescence. Quat. Sci. Rev. 14(4): 365-371.

Murray, A.S., Wintle, A.G.,2000. Luminescence dating of quartz using an improved single-aliquot regenerative-dose protocol. Radiat. Meas. 32, 57-73.

Murray, A.S., Thomsen, K.J., Masuda, N., Buylaert, J.P., Jain, M., 2012. Identifying well-bleached quartz using the different bleaching rates of quartz and feldspar luminescence signals. Radiat. Meas. 47(9), 688-695.

Precott, J.R., Hutton, J.T., 1994. Cosmic ray contributions to dose rates for luminescence and ESR: large depths and long-term time variations. Radiat. Meas. 23, 497-500.

Qin, Y.S., Yu, X.X., Chen, L.H., Liu, S., 2001. Spatial scale effects of runoff on the water resource con servation forest watershed with in the Miyun reservoir basin, Acta Ecologica Sinica. 21: 913-918.(In chinese)

Olley, J., Caitcheon, G., Murray, A. S., 1998. The distribution of apparent dose as determined by optically stimulated luminescence in small aliquots of fluvial quartz: Implications for dating young sediments. Quat. Sci. Rev. 17(11): 1033-1040.

Tang, C., van Asch, T.W.J., Chang, M., Chen, G.Q., Zhao, X.H., Huang, X.C., 2012. Catastrophic debris flows on 13 August 2010 in the Qingping area, southwestern China: The combined effects of a strong earthquake and subsequent rainstorms. Geomorphology. 139-140, 559-576.

Tu, X.F., 1994. Synthetical control of debris-flow in Fanzipai west gully, Beijing city. The Chinese journal of Geological Hazard and Control, 5,332-338 (in Chinese).

Thomsen, K.J., Murray, A.S., Bøtter-Jensen, L., 2005. Sources of variability in OSL dose measurements using single grains of quartz. Radiat. Meas. 39,47-61.

Thomsen, K.J., Murray, A.S., Bøtter-Jensen, L., Kinahan, J., 2007. Determination of burial dose in incompletely bleached fluvial samples using single grains of quartz. Radiat. Meas. 42 (3), 370-379

Thomsen, K.J., Murray, A.S., Jain, M., 2012. The dose dependency of the over-dispersion of quartz OSL single grain dose distributions. Radiat. Meas. 47(9), 732-739.

Winter, A.G., Murray, A.S., 2006. A review of quartz optically stimulated luminescence characteristics and their relevance in single-aliquot regeneration dating protocols. Radiat. Meas. 41, 369-391.

Wu, T.S., Jaiswal, M.K., Lin, Y.N., Chen, Y.W., Chen, Y.G., 2010. Residual luminescence in modern debris flow deposits from western Taiwan: A single grain approach. J Asian Earth Sci. 38, 274-282.

Xie, H., Zhong, D.L., Jin, H.C., 2001. Debris Flow and Landslide Disasters Control in Mountain Area of Beijing City, Bulletin of Soil and Water Conservation. 21, 37-39. (In chinese) 
Yang, Q.L., Gao, J.R., Wang, Y., Qian, B.T., 2011. Debris Flow Characteristics and Risk Degree Assessment in Changyuan Gully, Huairou District, Beijing. Procedia Earth and Planetary Science. 2, 262-271.

\section{Figure captions}

Figure 1: $\quad$ Map showing XXT catchment and diagram of sampling locations.

Figure 2: (a) Representative multi-grain (small) aliquot dose response curve (preheat $200{ }^{\circ} \mathrm{C}$ for $10 \mathrm{~s}$, cutheat $180{ }^{\circ} \mathrm{C}$ ) for sample XXT-2 showing recycling and recuperation (open symbols) and the interpolation of the sensitivity-corrected natural signal onto the dose response curve. Inset shows normalised luminescence signals from calibration quartz (closed triangles) and XXT-2 (open symbols). (b) Multi-grain thermal transfer measured using bleached aliquots of sample XXT-1. The arithmetic average dose of $0.13 \pm 0.03 \mathrm{~Gy}(\mathrm{n}=48)$ for all preheat temperature ranging between $180{ }^{\circ} \mathrm{C}$ and $280{ }^{\circ} \mathrm{C}$ is shown as a dashed line.

Figure 3: (a) Single-grain thermal transfer dose distribution for sample XXT-4. (b) Single-grain dose recovery distribution for sample XXT-4 with an added dose of 1 Gy. (c) as (b) but with an added dose of 4.5 Gy. (d) Absolute over-dispersion(OD, open circles) plotted against dose using data from (a), (b) and (c).The slope is $0.23 \pm 0.08$. Also shown (triangles) is the relationship between absolute standard deviation (stdev) and dose for the distributions shown in (a), (b) and (c). The linear fit to the data is shown by the dashed line.

Figure 4: Lower dose regions of the distributions and display the grains accepted by the IEU model (all grains retained) as grey filled symbols using an OD of $23 \%$ (see also Table 2). Insets focus in single-grain test dose (4.5 Gy) response plotted against $D_{e}$ for all natural samples. The two outliers discussed in the text are marked as black circles of sample XXT-3 and XXT-4. 
Figure 1
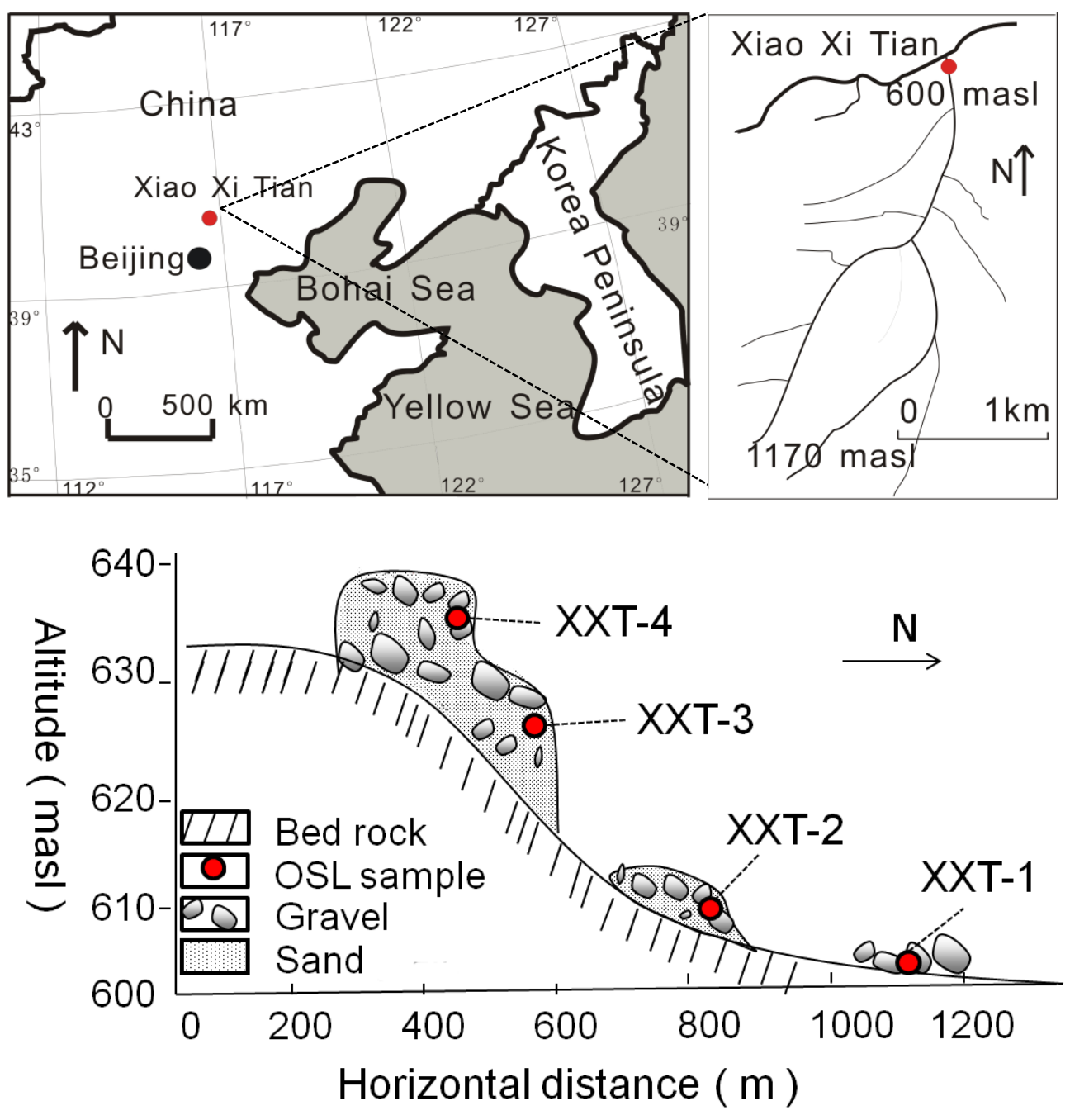
Figure 3

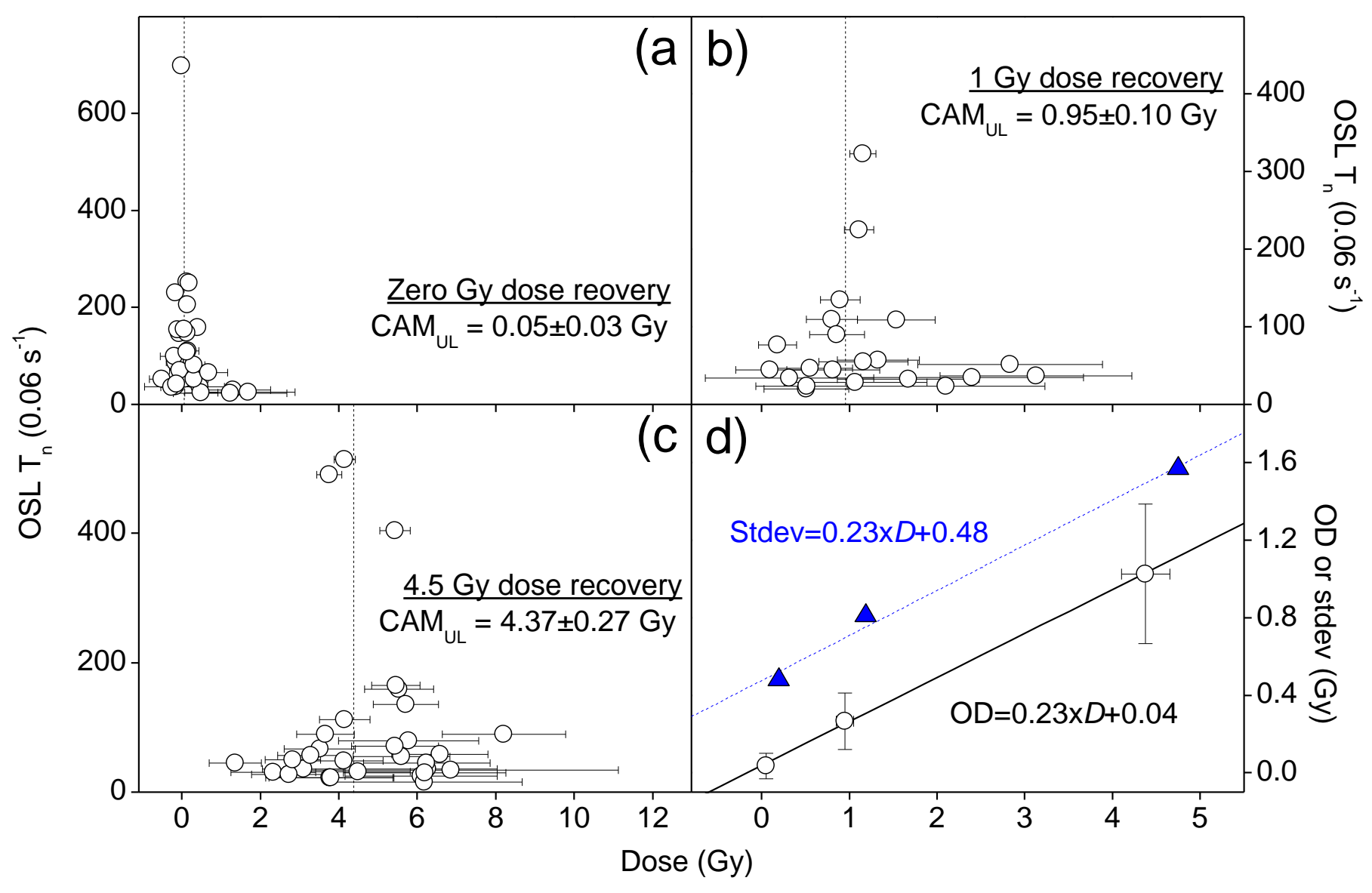


Figure 4

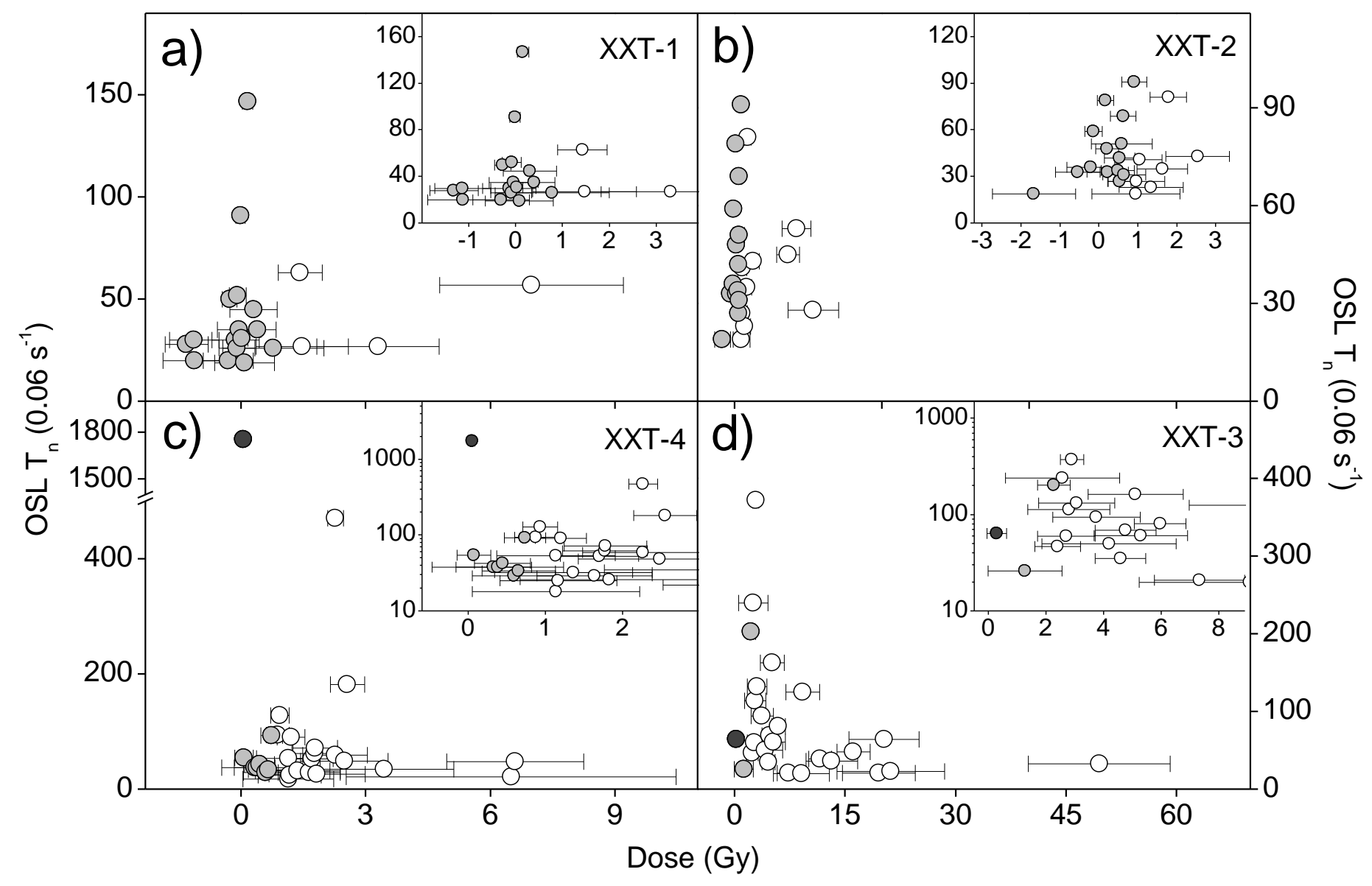




\begin{tabular}{|c|c|c|c|c|c|c|c|c|c|}
\hline \multirow{2}{*}{ Sample } & \multicolumn{2}{|c|}{ Depth w.c. } & \multicolumn{4}{|c|}{ Radionuclide concentrations $\left(\mathrm{Bq} \mathrm{kg}^{-1}\right)$} & \multicolumn{3}{|c|}{ Dose rate $\left(\right.$ Gy ka $\left.^{-1}\right)$} \\
\hline & $(\mathrm{m})$ & $(\%)$ & U-238 & Ra-226 & Th-232 & K-40 & $\operatorname{dry} \beta$ & dry $\mathrm{Y}$ & Total \\
\hline XXT-1 & 0.03 & 14 & $9 \pm 6$ & $18.2 \pm 0.5$ & $26.5 \pm 0.6$ & $781 \pm 16$ & $2.13 \pm 0.05$ & $1.05 \pm 0.02$ & $3.06 \pm 0.12$ \\
\hline XXT-2 & 0.04 & 17 & $38 \pm 9$ & $16.0 \pm 0.7$ & $28.2 \pm 0.7$ & $696 \pm 16$ & $2.05 \pm 0.05$ & $1.00 \pm 0.01$ & $2.88 \pm 0.11$ \\
\hline XXT-4 & 0.1 & 26 & $20 \pm 10$ & $21.0 \pm 0.8$ & $28.9 \pm 0.7$ & $559 \pm 16$ & $1.69 \pm 0.06$ & $0.93 \pm 0.02$ & $2.32 \pm 0.09$ \\
\hline XXT-3 & 10.6 & 13 & $11 \pm 10$ & $16.4 \pm 0.8$ & $33.3 \pm 0.8$ & $833 \pm 20$ & $2.30 \pm 0.06$ & $1.16 \pm 0.04$ & $3.10 \pm 0.14$ \\
\hline
\end{tabular}

Table1. Summary of depth, water content (w.c.), radionuclide concentrations and quartz dose rates for the three palaeo-debris samples. Water content is taken as midw ay between observed and saturated water content. An internal quartz dose rate of $0.06 \pm 0.03 \mathrm{mGy} \mathrm{a}^{-1}$ has been assumed. Total dose rate include cosmic rays and effect of water content. 


\begin{tabular}{|c|c|c|c|c|c|c|c|c|c|c|c|c|c|c|c|c|c|}
\hline \multirow{3}{*}{ Sample } & \multicolumn{2}{|l|}{$M G$} & \multirow{3}{*}{$\begin{array}{c}\text { CAMuL } \\
\text { (Gy) }\end{array}$} & \multirow{3}{*}{$\begin{array}{l}\text { ODuL } \\
(\%)\end{array}$} & \multirow[b]{3}{*}{$\mathrm{n} \quad \mathrm{N}$} & \multicolumn{8}{|c|}{ SG } & & & & \\
\hline & \multirow{2}{*}{$\begin{array}{c}\text { CAMuL } \\
\text { (Gy) }\end{array}$} & \multirow[b]{2}{*}{$\mathrm{n}$} & & & & \multicolumn{4}{|c|}{ IEU } & \multicolumn{4}{|c|}{ IEU rej. } & \multicolumn{4}{|c|}{ Unw. IEU } \\
\hline & & & & & & Dose (Gy) & $\mathrm{n}_{\mathrm{w} . \mathrm{b}}$ & $n_{w . b} / \mathrm{n}$ & $\begin{array}{l}\text { Sw.b. } \\
\text { (Gy) }\end{array}$ & Dose (Gy) & $\mathrm{n}_{\mathrm{w} . \mathrm{b}}$ & $n_{\text {w.b. }} / \mathrm{n}$ & $\begin{array}{l}\text { Sw.b. } \\
\text { (Gy) }\end{array}$ & Dose (Gy) & $\mathrm{n}_{\mathrm{w} . \mathrm{b}}$. & $n_{\text {w.b. }} / \mathrm{n}$ & $\begin{array}{l}\text { Sw.b } \\
\text { (Gy) }\end{array}$ \\
\hline XXT-1 & $0.62 \pm 0.12$ & 16 & $0.00 \pm 0.05$ & - & 203500 & $-0.03 \pm 0.07$ & 16 & 0.80 & 0.57 & - & - & - & - & $-0.24 \pm 0.14$ & 15 & 0.75 & 0.53 \\
\hline XXT-2 & $2.8 \pm 0.4$ & 18 & $0.7 \pm 0.2$ & $87 \pm 54$ & 243500 & $0.21 \pm 0.11$ & 14 & 0.58 & 0.66 & - & - & - & - & $0.3 \pm 0.2$ & 17 & 0.71 & 0.67 \\
\hline XXT-4 & $2.2 \pm 0.4$ & 17 & $1.2 \pm 0.2$ & $56 \pm 16$ & 282900 & $0.11 \pm 0.07$ & 8 & 0.29 & 0.25 & $0.84 \pm 0.12$ & 19 & 0.70 & 0.52 & $1.3 \pm 0.2$ & 26 & 0.93 & 0.84 \\
\hline XXT-3 & $4.7 \pm 0.4$ & 17 & $6.4 \pm 1.1$ & $71 \pm 24$ & 265000 & $0.6 \pm 0.6$ & 3 & 0.12 & 1.00 & $3.5 \pm 0.4$ & 16 & 0.64 & 1.60 & $2.1 \pm 0.3$ & 8 & 0.31 & 0.91 \\
\hline
\end{tabular}

Table2. Summary of multi-grain (MG) and single-grain (SG) dose estimates. 'CAMU'' is the unlogged central age model (Arnold et al., 2009). 'IEU' is the internal/external consistency minimum age

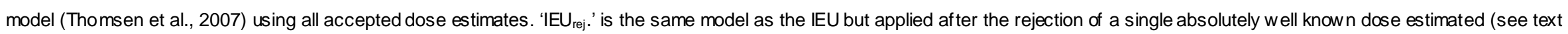
for detail). The IEU minimum doses have been calculated using a minimum relative over-dospersion of $23 \%$. The 'unw. IEU' is a unw eighted minimum age model similar to the approach suggested by Fuchs and Lang (2001) but adapted to accomodate a varying predicted standard deviation (see text for details). ' $n$ ' is the number of accepted aliquots/grains, ' $N$ ' is the number of total measured grains, ' $n_{w b}$.' is the number of grains identified to be well-bleached, and 'swb.' is the absolute standard deviation of the grains identified as beingwell-bleached. 


\begin{tabular}{ccccc}
\hline Sample & CAM $_{\text {UL }}(\mathrm{a})$ & IEU (a) & IEU $_{\text {rej. }}$ (a) & Unw. IEU (a) \\
\hline XXT-1 & $1 \pm 18$ & $-9 \pm 20$ & - & $-80 \pm 50$ \\
XXT-2 & $250 \pm 70$ & $70 \pm 40$ & - & $110 \pm 60$ \\
XXT-4 & $520 \pm 80$ & $50 \pm 30$ & $360 \pm 50$ & $570 \pm 80$ \\
XXT-3 & $2100 \pm 400$ & $180 \pm 200$ & $1120 \pm 140$ & $690 \pm 110$ \\
\hline
\end{tabular}

Table 3. Summary of single-grain ages. 'CAMu' is the unlogged central age model (Arnold et al., 2009). 'IEU' is the internal/external consistency minimum age model (Thomsen et al., 2007) using all accepted dose estimates. 'IEU rej.' is the same model as the IEU but applied after the rejection of a single absolutely well known dose estimated (see text for details). The IEU minimum doses have been calculated using a minimum relative over-dospersion of $23 \%$. The 'unw. IEU' is a unw eighted minimum age model similar to the approach suggested by Fuchs and Lang (2001) but adapted to accomodate a varying predicted standard deviation (see text for details). 